\title{
Effect of Parathyroid Hormone on Erythropoiesis
}

\author{
Dina Meytes, Eitan Bogin, Andrew Ma, Peter P. Dukes, and \\ Shaul G. MASSRY, Division of Nephrology and Department of Medicine, \\ University of Southern California School of Medicine, and Division of \\ Hematology and Oncology, Children's Hospital, Los Angeles, \\ California 90033
}

A B S T R A C T Inhibitors of erythropoiesis have been found in the blood of uremic patients but their nature has not been identified. These patients have excess blood levels of parathyroid hormone (PTH) and it is possible that PTH inhibits erythropoiesis. The present study was undertaken to examine the effect of intact PTH molecules and some of its fragments on human peripheral blood and mouse bone marrow burst-forming units-erythroid (BFU-E), on mouse bone marrow erythroid colony-forming unit (CFU-E), and granulocyte macrophage progenitors (CFU-GM), and evaluate the interaction between PTH and erythropoietin (Ep) on human BFU-E. Intact PTH (1-84 bPTH) in concentrations $(7.5-30 \mathrm{U} / \mathrm{ml})$ comparable to those found in blood of uremic patients produced marked and significant $(P<0.01)$ inhibition of BFU-E and mouse marrow GFU-GM, but not of mouse marrow CFU-E. Inactivation of 1-84 bPTH abolished its action on erythropoiesis. Increasing the concentration of $\mathrm{Ep}$ in the media from 0.67 to $1.9 \mathrm{U} / \mathrm{ml}$ overcame the inhibitory effect of $1-84$ bPTH on BFU-E. The N-terminal fragment of PTH (1-34 bPTH) and 53-84 hPTH had no effect on BFU-E.

The results deomonstrate that $(a)$ either the intact PTH molecule or a C-terminal fragment(s) bigger than 53-84 moiety exerts the inhibitory effect on erythropoiesis, and (b) adequate amounts of Ep can overcome this action of PTH. The data provide one possible pathway for the participation of excess PTH in the genesis of the anemia of uremia.

\section{INTRODUCTION}

Patients with chronic renal failure almost always have marked anemia (1-5). Decreased production $(3,5,6)$ and shortened survival of erythrocytes $(7-11)$ have been implicated as the cause of this abnormality. Re-

Dr. Meytes is the recipient of the Myron Karon Fellowship. Address correspondence to Dr. Massry at the University of Southern California School of Medicine.

Received for publication 9 June 1980 and in revised form 12 December 1980. duced availability of erythroprotein $(E p)^{1}(12-16)$ and the presence of inhibitors to various stages of erythropoiesis (5) could be responsible for the decrement in erythrocytes production. Indeed, uremic sera have been found to inhibit erythroid colony formation in vitro (17). The nature of these inhibitors are, as yet, unknown.

One prominent biochemical abnormality in renal failure is secondary hyperparathyroidism (18-20) and marked elevation in blood levels of parathyroid hormone (PTH) (21-23). Recently, PTH has been suggested to be a major uremic toxin underlying, at least partly, many of the manifestations of the uremic syndrome (24-26). It is theoretically possible that PTH affects erythropoiesis and, as such, the secondary hyperparathyroidism of renal failure participates in the pathogenesis of the anemia of uremia.

The present study was undertaken to investigate the effects of intact PTH and some of its fragments on erythroid colony formation and to investigate the interaction between PTH and Ep on erythropoiesis.

\section{METHODS}

The effects of PTH on the following hematopoietic progenitor cells were investigated: (a) human peripheral blood burstforming unit-erythroid (BFU-E), (b) mouse bone marrow BFU-E, $(c)$ mouse bone marrow erythroid colony-forming cells (CFU-E), (d) mouse bone marrow granulocyte macrophage (CFU-GM). Cells were cultured for BFU-E quantitation by the method of Iscove et al. (27) as modified by Ogawa et al. (28). Mononuclear cells were obtained from heparinized peripheral venous blood of healthy adult human subjects by centrifugation on Ficoll-Hypaque (Pharmacia Fine Chemicals, Piscataway, N. J.) at $400 \mathrm{~g}$ for $30 \mathrm{~min} ; 5 \times 10^{5}$ cells in $1 \mathrm{ml}$ final volume were plated in tissue culture dishes $(35 \times 10 \mathrm{~mm}$, 2-mm grid, Lux Scientific Corp., Newbury Park, Calif.). The cells were cultured in $\alpha$-medium (Flow Laboratories, Inc., Rockville, Md.) that contained $0.8 \%$ methylcellulose (Dow Chemical Co., Midland, Mich.), 30\% fetal calf serum (Gibco

\footnotetext{
${ }^{1}$ Abbreviations used in this paper: BFU-E, erythroid burstforming unit; bPTH, bovine PTH; CFU-E, erythroid colonyforming cells; CFU-GM, CFU granulocyte macrophage; $\mathrm{Ep}$, erythropoietin; PTH, parathyroid hormone.
} 
Laboratories, Grand Island Biological Co., Grand Island, N. Y.), $0.1 \mu \mathrm{mol} / \mathrm{ml}$ of $\alpha$-thioglycerol (Sigma Chemical Co., St. Louis, Mo.), $50 \mathrm{U} / \mathrm{ml}$ of penicillin, and $50 \mu \mathrm{g} / \mathrm{ml}$ of streptomycin; $1.3 \mathrm{U} / \mathrm{ml}$ of human EP (preparation OPR, $148.1 \mathrm{U} / \mathrm{mg}$ protein) was added when indicated.

Ep was kindly provided by the National Heart, Lung and Blood Institute, Bethesda, Md. It was collected and concentrated by the Department of Physiology, University of the Northeast, Corrientes, Argentina, and was further processed in the laboratory of Dr. Dukes of Children's Hospital at Los Angeles with the aid of National Institutes of Health grant HL 10880.

BFU-E were scored after $10-11 \mathrm{~d}$ of incubation in humidified atmosphere of $95 \%$ air and $5 \% \mathrm{CO}_{2}$ at $37^{\circ} \mathrm{C}$. Colonies consisting of three or more subcolonies of erythroid cells or large single accumulation of erythroid cells ( 500 cells) were defined as BFU-E derived colonies. Hemoglobinization of colonies was routinely verified using ortho-tolidine (J. T. Baker, Chemical Co., Phillipsburg, N. J.) as a heme-specific staining agent. A $4 \%$ (wt/vol) stock solution of ortho-tolidine $\left(3,3^{\prime}-\mathrm{di}\right.$ methylbenzidine) in glacial acetic acid was prepared. Immediately before staining, one part of stock solution was mixed with two parts of distilled water and one part of $3 \% \mathrm{H}_{2} \mathrm{O}_{2} ; 20$ drops of the staining solution were layered over the culture. Colonies were enumerated 1 min after staining under $\mathbf{4 0}$ magnification and direct illumination (29).

Mouse bone marrow was obtained from both femurs of 12-14-wk-old $\mathrm{CDF}_{1}$ mice weighing 25-30 g. In each mouse, BFU-E, CFU-E, and CFU-GM were tested simultaneously. For BFU-E, $2 \times 10^{5}$ marrow cells were plated in $1 \mathrm{ml}$ methylcellulose medium and stimulate with $2.6 \mathrm{U}$ of $\mathrm{Ep}$ (preparation T7E $3742 \mathrm{U} / \mathrm{mg}$ protein). After $7 \mathrm{~d}$ of incubation, cultures were stained and counted as described above. For CFU-E, 1.2 $\times 10^{5}$ marrow cells were plated in $1 \mathrm{ml}$ methycellulose medium and stimulated with $0.65 \mathrm{U}$ of $\mathrm{Ep}$ (preparation T7E) after $2 \mathrm{~d}$ of incubation colonies were counted. For CFU-GM, the agar culture method of Stanley and Metcalf was used (30). Suspensions of $1 \times 10^{5}$ marrow cells were plated in $1 \mathrm{ml}$ agar medium containing $15 \%$ fetal calf serum and $15 \%$ mouse embryo conditioned medium as the source of colony stimulating activity. After $7 \mathrm{~d}$ of incubation at $37^{\circ} \mathrm{C}$ in $10 \% \mathrm{CO}_{2}$ in air, colonies were counted under dissecting microscope at 10 magnification.

The effect of various concentrations of either intact bovine purified PTH (bPTH 1-84, Sigma Chemical Co.) or synthetic fragment 1-34 bPTH (Beckman Instruments, Inc., Spinco Div., Palo Alto, Calif.) was examined. In addition, the effect of synthetic human PTH containing 53-84 amino acids (53-84 hPTH, Bachem, Inc., Marina Del Rey, Calif.) was studied; 1.2 $\mu \mathrm{g}$ of this preparation is equivalent to $10 \mathrm{U}$ of intact PTH used in this study. The hormone or its fragments were dissolved in half strength $\alpha$-medium and sterilized by passage through silver metal membrane $0.45 \mu$ (Selas Flotronics, Huntington Valley, Pa.). A volume of $75 \mu \mathrm{l}$ of appropriate PTH solutions was added to $1-\mathrm{ml}$ cultures to provide the desired concentration of PTH in media. In addition, the effect of inactivation of PTH on BFU-E was also studied. 1-84 bPTH was inactivated as follows: $10-15 \mu \mathrm{g}$ of the PTH was dissolved in $60 \mu \mathrm{l} 0.15 \mathrm{~N}$ acetic acid and to this solution $40 \mu \mathrm{l}$ of $30 \% \mathrm{vol} / \mathrm{vol} \mathrm{H}_{2} \mathrm{O}_{2}$ was added. The solution was incubated at $37^{\circ} \mathrm{C}$ for $45 \mathrm{~min}$ and the reaction was terminated by freezing and lyophilizing.

To examine the interaction between PTH and Ep on erythroid colony formation, the concentration of Ep was varied in certain experiments from 0.67 to $1.9 \mathrm{U} / \mathrm{ml}$.

\section{RESULTS}

The effect of PTH on human peripheral blood BFU-E, mouse marrow BFU-E, CFU-E, and CFU-GM, and the interaction between PTH and Ep on human BFU-E are shown in Tables I through III in Fig. 1. The 1-84 bPTH had a significant inhibitory effect on both human and mouse BFU-E but not on mouse CFU-E. The inhibition of human BFU-E was apparent at a PTH concentation of $3.75 \mathrm{U} / \mathrm{ml}$, and further inhibition occurred by increasing the amount of PTH in the media with only $22 \pm 3 \%$ (SE) remaining colonies at $30 \mathrm{U} / \mathrm{ml}(P<0.01)$, Table I. It is important to emphasize that not only was the number of erythroid burst colonies remaining in the media containing PTH reduced, but also the number of subcolonies per burst was also significantly decreased; in a mouse bone marrow study the number of subcolonies in 10 bursts was 307 in the absence of PTH and 51 in the presence of PTH. 1-84 bPTH also significantly $(P<0.01)$ inhibited mouse marrow granulocyte macrophage progenitor cells. Inactivation of 1-84 bPTH abolished its inhibitory effect on human BFU-E (Table I).

Increasing the concentration of $\mathrm{Ep}$ in the media from

TABLE I

Effects of 1-34 bPTH and 1-84 bPTH on Human Peripheral Blood BFU-E

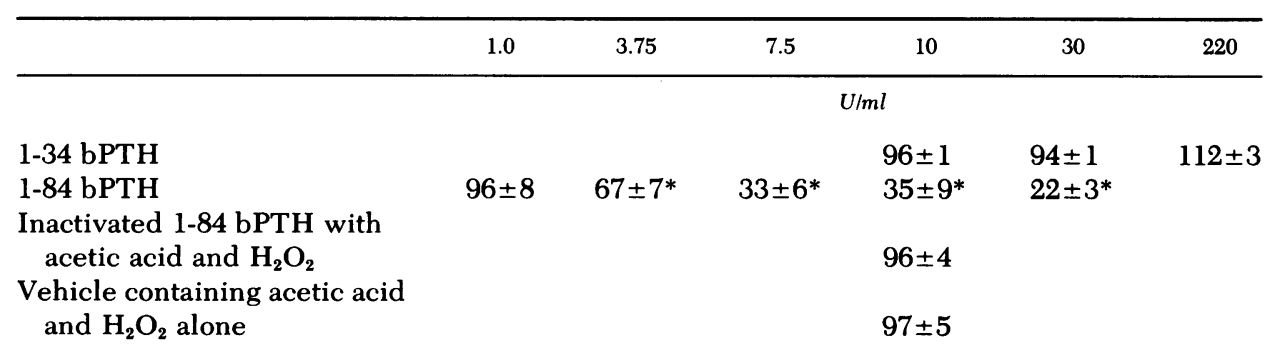

Data expressed as percent remaining colonies as compared with studies run in parallel without PTH. Each data point represents mean $\pm S E$ of three to six studies with each study made of five replicate plates.

* Indicate significant difference from control with $P<0.01$. 
TABLE II

Effects of 1-34 bPTH (20 U/ml) and 1-84 bPTH (20 U/ml) on Mouse Marrow Progenitor Cells

\begin{tabular}{lccc}
\hline & Day 2 CFU-E & Day 7 BFU-E & Day 7 CFU-GM \\
\hline $1-34$ bPTH & & $115 \pm 8$ & $107 \pm 6$ \\
$1-84$ bPTH & $100 \pm 4$ & $46 \pm 9^{*}$ & $39 \pm 10^{*}$ \\
\hline
\end{tabular}

Data expressed as percent remaining colonies as compared with studies run in parallel without PTH.

Each data point represent mean $\pm S E$ of two to four studies with each study made of four to five replicate plates.

${ }^{*}$ Indicates significant differences from control with $P<0.01$.

0.67 to $1.9 \mathrm{U} / \mathrm{ml}$ overcame the inhibitory effect of $1-84$ bPTH on human BFU-E. At the highest Ep concentration the number of colonies detected was $83 \pm 9 \%$, a value not significantly different from control (Fig. 1).

1-34 bPTH in a concentration up to $220 \mathrm{U} / \mathrm{ml}$ did not inhibit human BFU-E (Table I) and this fragment of PTH also had no effect on mouse marrow progenitor cells, Table II. The same batch of 1-34 bPTH stimulated the beating of heart cells (31) and increased the production of cyclic AMP by renal tubular cells (32) indicating that it was biologically active in other systems.

The effect of 53-84 hPTH on human peripheral blood BFU-E is shown in Table III. This fragment of PTH also did not have an inhibitory effect on BFU-E. In contrast, experiments with 1-84 bPTH carried out in parallel demonstrated significant and marked inhibition of BFU-E. In fact, the magnitude of the inhibition of

TABLE III

Effects of 53-84 hPTH and 1-84 bPTH on Human Peripheral Blood BFU-E

\begin{tabular}{cc}
\hline \multicolumn{1}{c}{ Experiment } & Number of colonies \\
\hline $\mathrm{I} \quad$ & \\
Control & $180 \pm 9$ \\
$53-84 \mathrm{hPTH}$ & $182 \pm 26$ \\
$1.2 \mu \mathrm{g} / \mathrm{ml}$ & $163 \pm 25$ \\
$3.6 \mu \mathrm{g} / \mathrm{ml}$ & $163 \pm 6$ \\
$12 \mu \mathrm{g} / \mathrm{ml}$ & $68 \pm 6^{*}$ \\
$1-84 \mathrm{bPTH}$ & \\
$10 \mathrm{U} / \mathrm{ml}$ & $170 \pm 22$ \\
$\mathrm{II} \quad$ & $144 \pm 13$ \\
Control & $149 \pm 3$ \\
$53-84 \mathrm{hPTH}$ & $173 \pm 5$ \\
$1.2 \mu \mathrm{g} / \mathrm{ml}$ & \\
$3.6 \mu \mathrm{g} / \mathrm{ml}$ & $79 \pm 3^{*}$ \\
$12 \mu \mathrm{g} / \mathrm{ml}$ & \\
$1-84 \mathrm{bPTH}$ & \\
$10 \mathrm{U} / \mathrm{ml}$ &
\end{tabular}

Each data point represents mean $\pm S E$ of five replicate plates. * Indicates significantly different from control with $P<0.01$.



FIGURE 1 Reversal of PTH* suppression by erythropoietin. Effect of increasing amounts of Ep on the inhibitory effect of 1-84 bPTH on human peripheral blood BFU-E. Each data point represents the mean $\pm S E$ of three studies with each study made of five replicate plates.

BFU-E by 1-84 bPTH in these experiments was similar to that observed in the earlier studies described above.

\section{DISCUSSION}

The results of the present study demonstrate that the intact PTH molecule (1-84 amino acids) inhibited erythropoiesis in vitro, whereas the $\mathrm{N}$-terminal fragment of PTH (1-34 amino acids) did not exert such an effect. This action of the hormone affected erythropoiesis at the stage of BFU-E and not at the stage of CFU-E. The demonstration that inactivated hormone lost its inhibitory effect on erythropoiesis indicates that this function is related to biological activity of the hormone. Furthermore, the observation that PTH inhibited BFU-E and not CFU-E argues against the notion that the effect was mediated by contaminant, such as endotoxin; the latter would have inhibited both BFU-E and CFU-E.

It is generally accepted that the $\mathrm{N}$-terminal fragment is an active moiety of PTH (33). This notion is based on the ability of this fragment to increase cyclic AMP production (34) but it does not necessarily imply that the 1-34 fragment has all the effects of the intact 1-84 molecule of PTH. Our studies show that on the erythropoiesis system, the $\mathrm{N}$-terminal fragment does not possess the action of the intact hormone. A corollary to our observation is the finding that 1-34 bPTH does not enhance glucose release by the liver, whereas the intact hormone does (35).

Several possibilities could be considered to explain the different effect of 1-34 and 1-84 bPTH on BFU-E. First, the erythroid cells may not have receptors for 1-34 PTH but have them for 1-84 PTH; our data do not provide information in this regard. Second, another frag- 
ment of the hormone is critical for the inhibitory effect of PTH on BFU-E. Our finding that 53-84 hPTH did not inhibit BFU-E would suggest that either the intact hormone or a bigger fragment of PTH, such as other Cterminal fragment(s) is needed for this inhibitory effect. Unfortunately, bigger C-terminal fragment(s) was not available to us for testing. However, if the C-terminal fragment(s) is the moiety that inhibits erythropoiesis in vitro, its accumulation in large quantities in the blood of the uremic patients (36) may play a major role in the pathogenesis of the anemia of uremia.

Levi et al. (37) reported that $8 \mathrm{U} / \mathrm{ml}$ of parathyroid extract (Eli Lilly \& Co., Indianapolis, Ind.) inhibited RNA synthesis and $2 \mathrm{U} / \mathrm{ml}$ was adequate to inhibit heme synthesis by mouse embryonic liver erythroid precursors. These observations are consistent with inhibitory role of PTH on erythrocyte maturation. Erslev et al. (38) mentioned in an abstract report that they did not find an effect of PTH on CFU-E. Although they did not provide detailed information on their observation, nor did they specify the preparation of PTH used, their results are in agreement with ours in regard to CFU-E.

Ohno et al. (17) found that uremic sera inhibited rabbit marrow CFU-E and BFU-E in the same way that PTH inhibited BFU-E in our study. They could not attribute their findings to altered blood levels of creatinine or quanidine compounds. It is possible that the effect of the uremic sera in their studies was due to excess PTH contained in the sera. Such an interpretation is consistent with our observations. However, one must assume that factors other than PTH were responsible for the inhibition of CFU-E in their studies.

The amounts of PTH used in our studies are comparable to those present in the blood of patients with advanced uremia. A concentration of $1 \mathrm{U} / \mathrm{ml}$ of $1-84 \mathrm{bPTH}$ in the reaction media is comparable to $20 \mu \mathrm{leq} / \mathrm{ml}$ as measured by our radioimmunoassay. Thus, 7.5 to $30 \mathrm{U} /$ $\mathrm{ml}$, which produced inhibition of erythropoiesis, are equivalent to $150-600 \mu \mathrm{leq} / \mathrm{ml}$, values commonly found in the blood of uremic patients. Therefore, it is plausible that the elevated blood levels of PTH in uremia produce a similar inhibition of erythrocyte cell formation.

The pathways through which excess blood levels of PTH in patients with renal failure may cause anemia are complex. Our data provide one possibility and suggest that secondary hyperparathyroidism of renal failure inhibits erythropoiesis and, as such, contributes to the degree of the anemia. Excess blood level of PTH may act through other mechanisms as well. Parathyroid hormone can induce hemolysis (39) and be responsible, at least partly, for the shortened survival of the erythrocytes. In addition, excess hormone causes bone marrow fibrosis and, indeed, an important component of bone disease in renal failure is marked fibrosis of the bone marrow cavity $(40,41)$. Such fibrosis reduces the availability of red marrow to produce erythrocytes.

Clinical observations support a role for excess PTH in the pathogenesis of the anemia of renal failure. Avram et al. (42) found in 12 dialysis patients that their hematocrit and reticulocytes increased and their blood transfusion requirements decreased after subtotal parathyroidectomy. Better et al. (43) also reported a significant rise in hemoglobin in four uremic patients after total parathyroidectomy and they mentioned one patient in whom hemoglobin increased from 4.0 to 9.0 $\mathrm{g} / 100 \mathrm{ml}$ after suppression of the activity of parathyroid glands by treatment with 1,25 dihydroxycholecalciferol. Anemia has also been reported in patients with primary hyperparathyroidism. Aurbach et al. (44) and Mallete et al. (45) found that 12 of $58(21 \%)$ patients with parathyroid adenoma had anemia that could not be explained by other causes; in seven of eight such patients, the anemia disappeared after parathyroidectomy. Furthermore, Boxer et al. (46) reported that 17 of their 322 patients with primary hyperparathyroidism $(5.1 \%)$ had unexplained normochronic, normocytic anemia. They also found that the blood levels of PTH were four times higher in the patients with anemia than in those without anemia. In seven of their patients in whom data were available before and after removal of the parathyroid adenoma, there were spontaneous and significant $(P$ $<0.01$ ) increments in hematocrit from $29.6 \pm 1.3(\mathrm{SE})$ to $40.1 \pm 1.5$.

The lower incidence and the milder degree of anemia in patients with primary hyperparathyroidism than in patients with uremia and secondary hyperparathyroidism should not be construed as evidence against a role for PTH in the pathogenesis of anemia. The lower blood levels of PTH, a possibly shorter duration of the disease, and the availability of normal kidneys and, hence, normal Ep production in patients with parathyroid adenoma may provide an explanation for the differences in the anemia between them and those with chronic renal failure.

The interaction between PTH and Ep on erythropoiesis deserves a comment. Our data showed that the inhibitory effect of PTH on BFU-E was counterbalanced by increasing the concentrations of $\mathrm{Ep}$ in the culture media. This finding provides the experimental basis for the understanding of the clinical observations reported by Caro et al. (16). These authors studied two groups of uremic patients with similar levels of hematocrit. One group had significantly higher blood levels of PTH and Ep, as well. Their data would suggest that the inhibitory effect of PTH on erythropoiesis in those with higher blood levels of hormone was overcome by the higher blood levels of Ep resulting in hematocrit levels similar to those noted in the patients with lower PTH levels and, hence, lesser inhibition of erythropoiesis. 
The interaction between PTH and Ep would suggest that patients with advanced chronic renal failure are in double jeopardy regarding their erythropoiesis. The excess blood levels of PTH inhibit erythrocyte formation and the inability to generate adequate Ep permits the inhibitory action of PTH to proceed unchecked. Such a combination of circumstances provide at least one explanation for the differences in the anemia between patients with renal failure and those with primary hyperparathyroidism who would have adequate Ep to counterbalance the action of PTH on erythropoiesis.

The observation that 1-84 bPTH also inhibited the mouse marrow granulocyte macrophage progenitor cells would suggest that leukopenia as well as anemia may develop in clinical conditions with excess PTH. However, leukopenia is not observed in primary or secondary hyperparathyroidism. It is conceivable that the availability of a factor analogous to Ep acting on the leukocyte system is not reduced in uremic patients or those with primary hyperparathyroidism and, therefore, may compensate for the inhibitory effect of PTH.

The cellular mechanism(s) through which PTH affects erythropoiesis are not elucidated. PTH stimulates calcium transport into mammalian cells (47-49). Alterations in transmembrane cation entry have important effects on cell proliferation and differentiation (50), and calcium has been implicated as intracellular messenger for these processes (51). It is theoretically plausible, therefore, that PTH affects erythropoiesis through the stimulation of calcium entry into erythroid cells.

Several lines of evidence support the calcium ion being an important regulator of erythropoiesis. Perris and Whitefield (52) reported that elevation of the blood concentration of calcium in the rat by calcium infusion or by PTH administration significantly increased mitotic activity of bone marrow within a few hours and this was followed by an increase in reticulocyte production suggesting stimulation of erythropoiesis (52). GallienLartigue (53) found that a calcium ionophore (A-23187) stimulated the proliferation rate of the hematopoietic stem cells of the mouse bone marrow as assayed by spleen colony-forming method (53). Finally, Misiti and Spivak (54) reported that small concentrations of calcium ionophore A-23187 (10 nM) enhanced Ep-induced erythroid colony formation.

If PTH enhances calcium entry into the erythroid cells and if calcium enhances cell proliferation, one would expect stimulation of erythroid colony formation rather than their inhibition by PTH. However, some of the observations metioned above were derived from acute experiments, and it is possible that prolonged exposure to large amounts of PTH is associated with greater changes in intracellular concentration of calcium that are adverse to cell function. The available information indeed suggest that stimulation or inhibition of erythropoiesis may be related to the amount of calcium available to the cells. Gallien-Latrigue found that the stimulation of erythroid colonies by calcium ionophore occurred when the concentration of the latter was $0.5-0.8 \mu \mathrm{g} / \mathrm{ml}$ but inhibition of colony formation was noted with a concentration of $1 \mu \mathrm{g} / \mathrm{ml}$ (53). The cytotoxic effect of the higher concentration of the ionophore was prevented by the addition of magnesium to the media; magnesium competed with calcium for the ionophore molecule and such a competition most probably resulted in reducing the rate of calcium influx into the cells. Misiti and Spivak (54) also found that increasing the calcium concentration in the culture media or addition of large concentrations of calcium ionophore A-23187 $(1 \mu \mathrm{M})$ suppress proliferation of erythroid colonies. Levi et al. (37) reported that small amounts of PTH stimulated mitotic activity and RNA and heme synthesis by erythroid precursors, while large amounts of the hormone inhibited these processes. Finally, it should be mentioned that the prolonged exposure of other tissues such as the brain or the peripheral nerves to excess PTH significantly increased their calcium content and was associated with disturbances in their function (55-60).

In summary, our data demonstrate that the intact molecule or a C-terminal fragment(s) bigger than 53-84 moiety inhibits erythropoiesis and this inhibitory effect could be overcome by adequate amounts of Ep. Our results, thus, provide new insight as to the pathogenesis of the decreased erythrocytes production in uremia and indicate that the excess blood levels of PTH, besides the reduced availability of $\mathrm{Ep}$, plays an important role in the overall process responsible for the anemia of uremia.

\section{ACKNOWLEDGMENTS}

The authors wish to express their appreciation to Ms. Jamie Jimenez and Ms. Gracy Fick for their assistance in the preparation of this manuscript.

This work was supported by contract AM 7-2218 and grant AM 26500 from the National Institutes of Health, and by a contract from the Department of Health of the State of California.

\section{REFERENCES}

1. Callen, J. R., and L. R. Limarzi. 1950. Blood and bone marrow studies in renal disease. Am. J. Clin. Pathol. 20: 3-23.

2. Roscoe, M. H. 1952. Anemia and nitrogen retention in patients with chronic renal failure. Lancet. I: 444-445.

3. Desforges, J. F. 1970. Anemia in uremia. Arch. Intern. Med. 126: 808-811.

4. Erslev, A. J. 1970. Anemia of chronic renal disease. Arch. Intern. Med. 126: 774-780.

5. Eschbach, J. W. 1976. Anemia. In Clinical Aspects of 
Uremia and Dialysis. S. G. Massry and A. L. Sellers, editors. Charles C Thomas, Springfield, Ill. 146-178.

6. Eschbach, J. W., J. W. Adamson, and J. D. Cook. 1970. Disorders of red blood cells production in uremia. Arch. Intern. Med. 126: 812-815.

7. Joske, R. A., J. M. McAlister, and T. A. J. Prankerd. 1956. Isotope investigations of red cell production and destruction in chronic renal disease. Clin. Sci. 15: 511-522.

8. Desforges, J. F., and J. P. Dawson. 1958. The anemia of renal failure. Arch. Intern. Med. 101: 326-332.

9. Kaye, M. 1958. The anemia associated with renal disease. J. Lab. Clin. Med. 52: 83-100.

10. Loge, J. P., R. D. Lange, and C. V. Moore. 1958. Characterization of the anemia associated with chronic renal insufficiency. Am. J. Med. 24: 4-18.

11. Shaw, A. B. 1967. Hemolysis in chronic renal failure. $B r$. Med.J. 1: 213-216.

12. Gurney, C. W., L. O. Jacobson, and E. Goldwasser. 1958. The physiologic and clinical significance of erythropoietin. Ann. Intern. Med. 49: 363-370.

13. Gallagher, N. I., J. M. McCarthy, K. T. Hart, and R. D. Lange. (1959). Evaluation of plasma erythropoietic-stimulating factors in anemic uremic patients. Blood. 14: 662667.

14. Naets, J., and A. F. Heuse. 1962. Measurement of erythropoietic stimulating factor in anemic patients with or without renal disease. J. Lab. Clin. Med. 60: 365-374.

15. Brown, R. 1965. Plasma erythropoietin in chronic uremia. Br. Med. J. 2: 1036-1038.

16. Caro, J., S. Brown, O. Miller, T. Murray, and A. J. Erslev. (1979). Erythropoietin levels in uremic nephric and anephric patients. J. Lab. Clin. Med. 93: 449-58.

17. Ohno, Y., A. B. Rege, J. W. Fisher, and J. Barona. 1978. Inhibitors of erythroid colony formation (CFU-E and BFU-E) in sera of azotemic patients with anemia of renal disease. J. Lab. Clin. Med. 92: 916-923.

18. Pappenheimer, A. M., and S. L. Wilens. 1935. Enlargement of the parathyroid glands in renal disease. Am. J. Pathol. 11: 73-91.

19. Roth, S. I., and R. B. Marshall. 1969. Pathology and ultrastructure of the human parathyroid glands in chronic renal failure. Arch. Intern. Med. 124: 397-406.

20. Katz, A. I., C. L. Hampers, and J. P. Merrill. 1969. Secondary hyperparathyroidism and renal osteodystrophy in chronic renal failure. Medicine (Baltimore). 48: 333-374.

21. Berson, J. A., and R. S. Yalow. 1966. Parathyroid hormone in plasma in adenomatous hyperparathyroidism, uremia and bronchogenic carcinoma Science (Wash. D. C.). 154: 907-909.

22. Massry, S. G., J. W. Coburn, M. Peacock, and C. R. Kleeman. 1972. Turnover of endogenous parathyroid hormone in uremic patients and those undergoing hemodialysis. Trans. Am. Soc. Artif. Intern. Organs. 18: 416-422.

23. Arnaud, C. D. 1973. Hyperparathyroidism and renal failure. Kidney Int. 4: 89-95.

24. Massry, S. G. 1977. Is parathyroid hormone a uremic toxin? Nephron. 19: 125-130.

25. Massry, S. G., and Goldstein, D. A. 1978. Role of parathyroid hormone in uremic toxicity. Kidney Int. 12: S39-42.

26. Massry, S. G., and D. A. Goldstein. 1979. The search for uremic toxin(s) "x": "x" $\times$ PTH. Clin. Nephrol. 11 $181-189$.

27. Iscove, N. N., F. Sieber, and K. H. Winterhalter. 1974. Erythroid colony formation in culture of mouse and human bone marrow: analysis of the requirement of erythropoietin by gel filtration and affinity chromatography on agarose-concanavalin. J. Cell. Physiol. 83: 309-320.

28. Ogawa, M., O. C. Grush, R. F. O'Dell, H. Hara, and M. D. MacEachern. 1977. Circulating erythroid precursors assessed in culture: characterization in normal man and patients with hemoglobinopathies. Blood. 50: 1081-1092.

29. Meytes, D., A. Ma, J. A. Ortega, N. A. Shore, and P. P. Dukes. 1979. Human erythroid burst-promoting activity produced by phytohemagglutinin-stimulated, radioresistant peripheral blood mononuclear cells. Blood 54: 10501057.

30. Stanley, E. R., and D. Metcalf. 1969. Partial purification and some properties of the factor in normal and leukemic human urine stimulating mouse bone marrow colony growth in vitro. Aust. J. Exp. Biol. Med. Sci. 47: 467-482.

31. Bogin, E. S. G. Massry, and I. Harary. 1980. Effect of parathyroid hormone (PTH) on heart cells. Clin. Res. 28: 555A (Abstr.).

32. Chase, L. R., and G. D. Aurbach. 1968. Renal adeny cyclase: anatomically separate sites for parathyroid hormone and vasopressin. Science (Wash. D. C.) 159: 545547.

33. Aurbach, G. D., H. T. Keutmann, H. D. Naill, G. W. Tregear, J. L. H. O’Riordan, R. Marcus, S. J. Marx, and J. T. Potts, Jr. 1972. Structure, synthesis, and mechanism of action of parathyroid hormone. Recent Prog. Horm. Res. 28: 353-398.

34. Canterbury, J. M., G. S. Levey, and E. Reiss. 1973. Activation of renal cortical adenylate cyclase by circulating immunoreactive parathyroid hormone fragments. J. Clin. Invest. 52: 524-527.

35. Hruska, K. A., J. Blondin, R. Bass, J. Santiago, T. Lorraine, P. Altsheler, K. Martin, and S. Klahr. 1979. Effect of intact parathyroid hormone on hepatic glucose release in the dog. J. Clin. Invest. 64: 1016-1023.

36. Freitag, J., K. J. Martin, K. A. Hruska, C. Anderson, M. Conrades, J. Landenson, S. Klahr, and E. Slatopolsky. 1978. Impaired parathyroid hormone metabolism in patients with chronic renal failure. N. Engl. J. Med. 298 ; 29-32.

37. Levi, J., H. Bessler, I. Hirsch, and M. Djaldetti. 1979. Increased RNA and heme synthesis in mouse erythroid precursors by parathyroid hormone. Acta Haematol. 61: 125-129.

38. Erslev, A. J., T. Connelly, and J. Caro. 1979. The role of parathyroid hormone on erythropoiesis. Proceedings of Conference on Aplastic Anemia, a Stem Cell Disease, San Francisco, June 17-19, (Abstract).

39. Massry, S. G., E. Bogin, D. Meytes, G. Bristol, J. Smith, and P. P. Dukes. 1980. Effect of parathyroid hormone (PTH) on red blood cells (RBC) and on erythropoiesis. Clin. Res. 28: 535A (Abstr.).

40. Weinberg, S. G., A. Lubin, S. N. Weiner, M. P. Deoras, M. K. Ghose, and R. C. Kopelman. 1977. Myelofibrosis and renal osteodystrophy. Am. J. Med. 63: 755-764.

41. Malluche, H. H., D. A. Goldstein, and S. G. Massry. 1979 Management of renal osteodystrophy with $1,25(\mathrm{OH})_{2} \mathrm{D}_{3}$. II. Effects on histopathology of bone: evidence for healing of osteomalacia. Miner. Electrolyte Metab. 2: 48-55.

42. Avram, M. M., H. Alexis, M. Rahman, B. Son, and M. Iancu. 1971. Decreased transfusional requirement following parathyroidectomy in long term hemodialysis. Proc. Am. Soc. Nephrol. 5: 5. (Abstract).

43. Better, O. S., S. M. Shasha, J. Winaver, and C. Chaimovitz. 1976. Improvement in the anemia of hemodialysis patients following parathyroidectomy (PTX). Proc. Am. Soc. Nephrol. 9: 1 (Abstr.). 
44. Aurbach, G. D., L. E. Mallette, B. M. Patten, D. A. Heath, J. L. Doppman, and J. P. Bilezikian. 1973. Hyperparathyroidism: Recent studies. Ann. Intern. Med. 79: 566-581.

45. Mallete, L. A., J. P. Bilezikian, D. A. Heath, and G. D. Aurbach. 1974. Primary hyperparathyroidism: clinical and biochemical features. Medicine (Baltimore). 53: 127-146.

46. Boxer, M., L. Ellman, R. Geller, and C. Wang. 1977. Anemia in primary hyperparathyroidism. Arch. Intern. Med. 137: 588-593.

47. Borle, A. B. 1968. Calcium metabolism in Hela cells and the effect of parathyroid hormone. J. Cell Biol. 36: 567-582.

48. Borle, A. B. 1970. Kinetic analysis of calcium movement in cell cultures. III. Effect of calcium and parathyroid hormone on kidney cells. J. Gen. Physiol. 55: 163-186.

49. Borle, A. B. 1973. Calcium metabolism at the cellular level. Fed. Proc. 32: 1944-1950.

50. Kaplan, J. G. 1978. Membrane cation transport and the control of proliferation of mammalian cells. Annu. Rev. Physiol. 40: 19-41.

51. Rasmussen, H., and D. B. P. Goodman. 1977. Relationship between calcium and cyclic nucleotide in cell activation. Physiol. Rev. 57: 421-509.

52. Perris, A. D, and J. F. Whitefield. 1971. Calcium homeostasis and erythropoietic control in the rat. Can.J. Physiol. Pharmacol. 49: 22-35.

53. Gallien-Lartigue, O. 1976. Calcium and ionophore A-23187 as initiator of DNA replication in the pluripotent hematopoietic stem cell. Cell. Tissue Kinet. 9: 533-540.

54. Misiti, J., and J. L. Spivak. 1979. Erythropoiesis in vitro. Role of calcium. J. Clin. Invest. 64: 1573-1579.

55. Arieff, A. I., and S. G. Massry. 1974. Calcium metabolism of brain in acute renal failure. J. Clin. Invest. 53: 387392.

56. Guisado, R., A. I. Arieff, and S. G. Massry. 1975. Changes in the electroencephalogram in acute uremia. J. Clin. Invest. 53: 738-745.

57. Goldstein, D. A., and S. G. Massry. 1978. Effect of parathyroid hormone administration and its withdrawal on brain calcium and electroencephalogram. Miner. Electrolyte Metab. 1: 84-91.

58. Goldstein, D. A., L. A. Chui, and S. G. Massry. 1978. Effect of parathyroid hormone and uremia on peripheral nerve calcium and motor nerve conduction velocity. J. Clin. Invest. 61: 88-93.

59. Cogan, M. G., C. M. Covey, A. I. Arieff, A. Wisniewski, O. H. Clark, V. Lazarowitz, and W. Leach. 1978. Central nervous manifestation of hyperparathyroidism. Am. J. Med. 65: 963-70.

60. Goldstein, D. A., E. I. Feinstein, L. A. Chui, R. Pattabhiraman, and S. G. Massry. 1980. The relationship between the abnormality in electroencephalogram and blood levels of parathyroid hormone in dialysis patients. J. Clin. Endocrinol. Metab. 51: 130-134. 